\title{
Processos de significação de afásicos usuários de comunicação suplementar e/ou alternativa
}

\author{
Meaning attribution processes of aphasic users of augmentative \\ and alternative communication
}

\author{
Regina Yu Shon Chun ${ }^{1}$
}

\begin{abstract}
RESUMO
Este trabalho volta-se ao estudo da Comunicação Suplementar e/ou Alternativa (CSA) na afasia sob uma perspectiva discursiva, assumindo caráter original e fundamental. Interessa investigar processos de significação de afásicos não fluentes, usuários de CSA por meio de estudo de caso longitudinal e qualitativo de cinco sujeitos com idades, dificuldades linguísticas e tipos de afasia variados, acompanhados em grupo fonoaudiológico. Os dados foram gravados em vídeo de 2006 a 2008, analisando-se episódios relevantes aos objetivos da investigação. Os resultados evidenciaram que a CSA possibilita processos de significação diversos. Os sujeitos realizaram traduções linguísticas, em termos jakobsonianos: do símbolo à palavra, do gesto à palavra, do desenho à palavra e da circulação entre sistemas verbais e não-verbais. A CSA mostrou-se eficaz nas atividades linguísticas dos sujeitos estudados, produzindo efeitos na qualidade de sua interação social.
\end{abstract}

Descritores: Afasia; Comunicação não verbal; Linguagem; Terapia de linguagem

\section{INTRODUÇÃO}

Diversos agravos à saúde afetam as atividades linguísticocognitivas dos sujeitos, dentre as quais, a doença cérebro vascular (DCV), causa importante de morbidade e mortalidade da população em geral, sendo que a mortalidade proporcional por doenças do aparelho circulatório é de 32,3\%, liderando as causas de óbito no Brasil, conforme dados do Ministério da Saúde de $1997^{(1)}$. A DCV ocupa o primeiro lugar dentre essas causas, sendo que dados epidemiológicos americanos mostram estimativas de que pelo menos $50 \%$ dos casos neurológicos atendidos em hospitais gerais sejam decorrentes da $\mathrm{DCV}^{(1)}, \mathrm{o}$ que evidencia o impacto na saúde desse grupo populacional e a importância da reabilitação nesses casos.

$\mathrm{O}$ acidente vascular cerebral (AVC) agrega um grupo de doenças com manifestações clínicas semelhantes, de diferentes etiologias, que "representa grande ônus em termos sócioeconômicos, pela alta incidência e prevalência de quadros

Trabalho realizado no Curso de Fonoaudiologia da Faculdade de Ciências Médicas da Universidade Estadual de Campinas - UNICAMP - Campinas (SP), Brasil.

(1) Doutora, Professora do Curso de Fonoaudiologia e do Mestrado Profissional Saúde, Interdisciplinaridade e Reabilitação da Faculdade de Ciências Médicas da Universidade Estadual de Campinas - UNICAMP - Campinas (SP), Brasil.

Endereço para correspondência: Regina Yu Shon Chun. Rua Tessália Vieira de Camargo, 126. Cidade Universitária “Zeferino Vaz" - Campinas/SP - CEP:

13083-887. E-mail: reginayu@ @fcm.unicamp.br

Recebido em: 29/10/2009; Aceito em: 2/5/2010 sequelares. A importância da DCV para o Sistema de Saúde no Brasil pode ser estimada pelo fato de representar $8,2 \%$ das internações e $19 \%$ dos custos hospitalares do Instituto Nacional de Assistência Médica da Previdência Social”"(1) Dentre as sequelas decorrentes do AVC, encontram-se as afasias.

As afasias são resultantes de lesões cerebrais adquiridas e podem ser classificadas como fluentes e não fluentes. Dependendo do tipo e do grau de lesão, decorrem das afasias dificuldades linguísticas como: produção oral reduzida, dificuldade de evocação de palavras e de manutenção de tópicos discursivos, fala entrecortada, parafasias, alterações de praxia bucofacial, etc. ${ }^{(2)}$. Alterações que limitam o desenvolvimento pessoal e podem restringir as experiências interpessoais ${ }^{(3)}$, bem como as dificuldades de produção/interpretação verbal tendo efeitos na interação social desse grupo populacional ${ }^{(4)}$.

Há que se considerar que os avanços tecnológicos no campo da Saúde têm possibilitado maior sobrevida das pessoas com alterações ou disfunções neurológicas, gerando consequente aumento da demanda de atendimento desse grupo, como no caso das afasias, que, dentre outros aspectos, necessitam de formas alternativas para se comunicar ${ }^{(4)}$, como a Comunicação Suplementar e/ou Alternativa (CSA) pode proporcionar.

A CSA trata-se de abordagem clínico-educacional que visa, de forma temporária ou permanente, apoiar, complementar, suplementar/melhorar ou substituir as formas de produção e interpretação verbal de sujeitos não falantes ou com dificuldades de linguagem ${ }^{(4)}$. Nessa direção, a CSA assume grande relevância no acompanhamento fonoaudiológico da afasia, 
sendo que sua aplicação encontra-se mais difundida no âmbito internacional ${ }^{(5-8)}$ do que no cenário nacional ${ }^{(9)}$.

Do mesmo modo, a conceituação e a mensuração da incapacidade ganha cada vez maior interesse, especialmente pelo aumento da sobrevida de pessoas com doenças crônicas ${ }^{(10)}$. As autoras desse estudo pontuam que há necessidade de maior clareza na definição de conceitos como incapacidade e deficiência. Nesse sentido, a Classificação Internacional de Funcionalidade, Incapacidade e Saúde (CIF), proposta pela Organização Mundial de Saúde, assume grande relevância para a compreensão da incapacidade e da deficiência a partir de aspectos funcionais e contextuais ${ }^{(10)}$.

Este trabalho visa abordar como os sujeitos afásicos, particularmente aqueles com expressão verbal reduzida, atuam com as dificuldades de linguagem e nesse processo, a contribuição da CSA em uma perspectiva discursiva de linguagem, considerando-se aspectos funcionais e contextuais no desempenho linguístico desses sujeitos. Segue-se uma abordagem em que os processos patológicos de linguagem são analisados como atividade constitutiva da linguagem, do sujeito e de suas interações sociais ${ }^{(2)}$.

A abordagem da CSA frequentemente é associada a tarefas descontextualizadas de reconhecimento, nomeação e/ou ao treinamento do apontar de símbolos ${ }^{(11-13)}$. De modo que, estudá-la sob a perspectiva da neurolinguística discursiva ${ }^{(14)}$ assume caráter original e fundamental, além de possibilitar investigar os processos de significação envolvidos nas atividades linguístico-cognitivas dos afásicos de forma contextualizada e discursivamente orientada.

A motivação teórico-clínica da formulação dos processos de significação na afasia justifica-se por envolver aspectos verbais e não-verbais além da incompletude do que é dito ${ }^{(14)}$. Tal condição leva a que o sujeito afásico busque outros arranjos para significar, isto é, que produza processos alternativos de significação. Tais processos podem ser analisados em termos jakobsonianos, ou seja, como tradução de um sistema semiótico para outro.

Nesse sentido, retoma-se a sugestão ${ }^{(14)}$, acerca da afasia, de pensar a CSA como forma de tradução semiótica:

“... Um sujeito é afásico quando lhe faltam recursos de produção e interpretação para exercer a linguagem, sem, no entanto, lhe faltar a função cognitiva/psíquica de poder traduzir (...), por meio de processos alternativos de significação, o que quer dizer."

Além disso, outros autores ${ }^{(6,15)}$ estudaram qual tipo de afasia se beneficiaria da CSA, o momento da intervenção e os recursos necessários, concluindo que os afásicos podem se beneficiar dessa intervenção ${ }^{(15)}$ e que a CSA contribui nos casos de distúrbios adquiridos de linguagem para maior efetividade de comunicação/participação nas atividades diárias ${ }^{(7)}$, o que justifica estudos como o aqui proposto.

\section{APRESENTAÇÃO DOS CASOS CLÍNICOS}

Este trabalho foi aprovado pelo Comitê de Ética em Pesquisa da Faculdade de Ciências Médicas da Universidade Estadual de Campinas (UNICAMP), sob n ${ }^{\circ}$ 417/2006. Serão focalizados dados-achados de 2006 a 2008.
A pesquisa foi explicada aos sujeitos envolvidos (e/ou seus responsáveis), os quais, após anuência, assinaram o Termo de Consentimento Livre e Esclarecido, consentindo com a realização e a divulgação desta pesquisa e seus resultados conforme Resolução 196/96 (Brasil, Resolução MS/CNS/ CNEP no 196/96 de 10/10/1996).

Todos os sujeitos são participantes do Grupo II do Centro de Convivência de Afásicos (CCA) e do grupo fonoaudiológico de CSA. O CCA foi criado com o objetivo de desmedicalizar a assistência ao afásico e criar um espaço onde o sujeito pudesse fazer uso de seu direito de se expressar. Além das atividades de convivência, que propiciam uma dinâmica interativa entre afásicos e não afásicos, é também um centro de pesquisas e estudos neurolinguísticos ${ }^{(14)}$. Essa estrutura de grupo, baseada em práticas discursivas, proporcionou condições para a inserção da CSA.

São apresentados cinco casos clínicos, de sujeitos afásicos não fluentes, de diferentes idades e comprometimentos diversos de linguagem, usuários de CSA. Os sujeitos participam de encontros semanais de fonoaudiologia em que se introduziu a CSA. Os mediadores do grupo envolveram, ao longo do estudo, além da pesquisadora, diferentes alunos do Curso de Graduação em Fonoaudiologia, do Programa de Aprimoramento de Fonoaudiologia e do Mestrado Profissional da UNICAMP.

Para o desenvolvimento do trabalho foram construídas pranchas individuais de comunicação, utilizando-se os símbolos do Sistema Pictográfico de Comunicação (SPC) além de outros recursos como os vocalizadores Go Talk e VoicePod. Foram desenvolvidas atividades discursivas de linguagem envolvendo: agenda interativa, música, poesia, leitura de jornais, jogos, receitas de culinária e de artesanato, relatos de histórias de vida dos sujeitos, nas quais se observou que estes buscavam diferentes arranjos para se comunicar e utilizavam processos de significação diversos, apresentados adiante.

Considerando-se que a linguagem dos sujeitos é produzida em espaço interativo, suas manifestações são analisadas no contexto de interlocução. Os encontros foram gravados em vídeo. Os episódios mais relevantes foram transcritos ortograficamente para análise em relação aos processos de significação utilizados pelos sujeitos, isto é, quanto às possibilidades de traduções, em termos jakobsonianos, por meio da linguagem/ uso da CSA, ou seja, de operações semióticas do símbolo à palavra, do símbolo ao gesto e da palavra ao símbolo.

\section{Sujeito 1}

Dados pessoais: 49 anos, gênero feminino, solteira, terapeuta ocupacional. Apresenta uma afasia que incide sobre sua expressão verbal, manifestada por repetições constantes com estereotipias verbais, dificuldade de encadear o discurso, além de hemiparesia à direita. Beneficia-se da relação dialógica e do prompting auditivo e visual. Há vários anos participa do CCA, sendo que a convivência nesse espaço a tem ajudado a retomar regras sociais, cujo uso foi modificado pela afasia.

Grupo de CSA: observa-se que gosta de conversar, apoia-se na oralidade e apresenta estereotipias verbais, como: "preciso falar" e "ótimo". Participa ativamente das atividades, apresentando iniciativa discursiva e respeito aos turnos dos 
outros. Demonstra grande interesse na CSA, sendo que seu uso contribui para aumento do fluxo discursivo. Apresenta importante papel no grupo de CSA, incentivando a participação e a produção oral dos demais sujeitos, o que também favorece sua oralidade e acesso lexical.

No começo do estudo, apoiava-se no correspondente escrito acima do símbolo de CSA, copiando a palavra escrita, ao mesmo tempo em que falava, geralmente após incentivo oral do interlocutor. Tal fato mostra uma das possibilidades de tradução inter-semiótica nos estados de afasia ${ }^{(14)}$. Verifica-se que o Sujeito 1 se apoia na palavra escrita para chegar à palavra falada (desejada). É interessante notar que no decorrer da implementação do trabalho com a CSA há modificação nesse processo de significação (da palavra escrita à palavra falada). O sujeito começa a usar como referência principal o desenho dos símbolos do Sistema Pictográfico de Comunicação (SPC) e não mais o referente escrito. No decorrer do estudo, observa-se que se apoia em ambos - desenho e referente escrito - como também no incentivo oral do interlocutor, ou seja, inicialmente, ao utilizar os símbolos do SPC, o processo de significação mais frequente era do desenho à palavra, como ilustra a Figura 1.

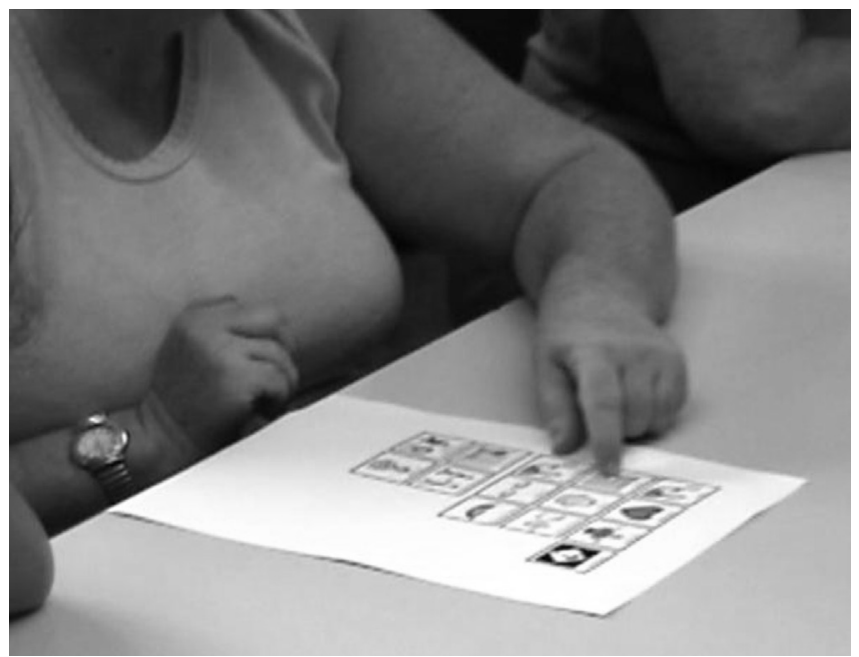

Figura 1. Do símbolo à palavra falada

Nessa atividade, o sujeito seguia a letra da música "Carinhoso", apresentada ao grupo por meio dos símbolos do SPC (Figura 2).

Ao longo da investigação, observa-se que a construção de frases por meio da CSA favorece a organização e a produção linguística deste sujeito, o qual se beneficiou do trabalho desenvolvido. Observa-se aumento da oralidade e favorecimento do acesso lexical desse sujeito.

\section{Sujeito 2}

Dados pessoais: 57 anos, gênero feminino, não alfabetizada, casada, oito filhos. Apresenta sequela de AVCI - afasia com hemiparesia à direita com predomínio braquial. Tomografia computadorizada indica lesão fronto-parieto-temporal à esquerda. Segundo dados dos prontuários institucionais, apresenta falta de iniciativa discursiva, sendo necessário, na maioria das situações dialógicas que o outro elicie a conversação por
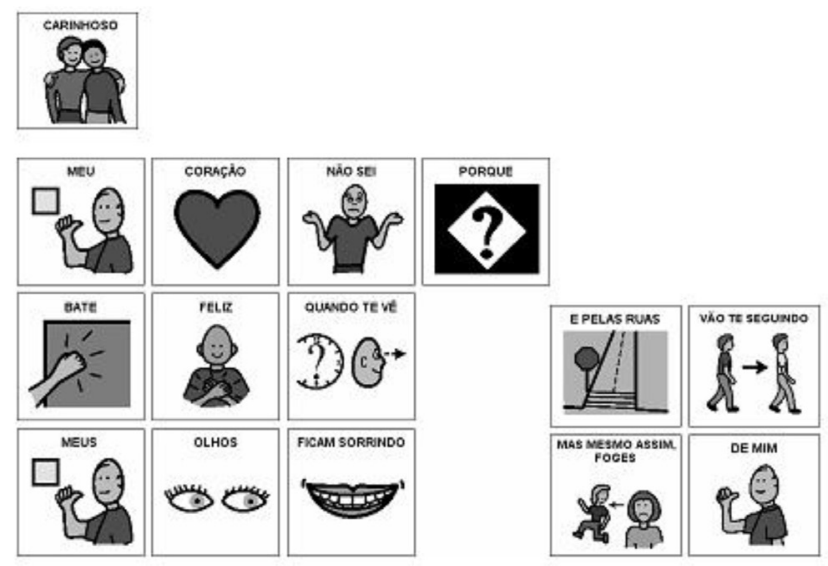

Figura 2. Trecho da música "Carinhoso", adaptada com os símbolos do Sistema Pictográfico de Comunicação

meio de perguntas ou oferecendo incentivo. Frequentemente, desistia de falar e chamava o marido para falar por ela.

Grupo de CSA: Desde o início, não demonstrou dificuldade na utilização da CSA. No entanto, apresentou frequência assistemática no grupo CSA, tendo interrompido sua participação alguns meses após a finalização da coleta de dados. Como suas produções linguísticas por meio da CSA foram sempre adequadas, verifica-se que pode se beneficiar deste recurso quando precisar. Vale observar que poucas vezes recorreu ao marido para auxiliá-la, como fazia anteriormente. É interessante notar o quanto a CSA favoreceu sua produção linguística, bem como uma participação mais ativa nas atividades, possibilitando que expressasse suas ideias e desejos com maior clareza.

Outro exemplo significativo de sua evolução linguística ocorreu em uma atividade de construção coletiva de poesia, quando se observou que a CSA favoreceu a abstração linguística necessária. O sujeito produziu do símbolo à fala, o título: "Amigos, amigos e coração" bem como o reproduziu oralmente no VoicePod (Figura 3). Além da pista visual propiciado pelos símbolos e da pista auditiva proporcionada pelo interlocutor, ouvir a própria voz reproduzida nesse equipamento representou uma nova possibilidade para o indivíduo atualizar seu discurso, produzindo o enunciado desejado. Verifica-se a circulação do sujeito entre os vários sistemas semióticos na produção dos processos de significação, além do VoicePod se evidenciar como importante recurso no processo terapêutico desse sujeito.

\section{Sujeito 3}

Dados pessoais: 65 anos, gênero feminino, casada, professora aposentada, pedagoga. Apresenta uma afasia que incide na produção oral que também se caracteriza por uma apraxia buco-facial. O episódio lesional foi desencadeado por crise de hipertensão e a tomografia indicou hematoma frontal esquerdo (acometimento de estruturas corticais e sub-corticais anteriores). Utiliza a escrita para se comunicar, faz leitura esporádica de revistas e do jornal da cidade, não demonstrando dificuldades de interpretação do texto. Sua fala é entrecortada, permeada de anomias, parafasias fonológicas e de prolongamentos com sincinesias, enquanto procura os gestos articulatórios. 


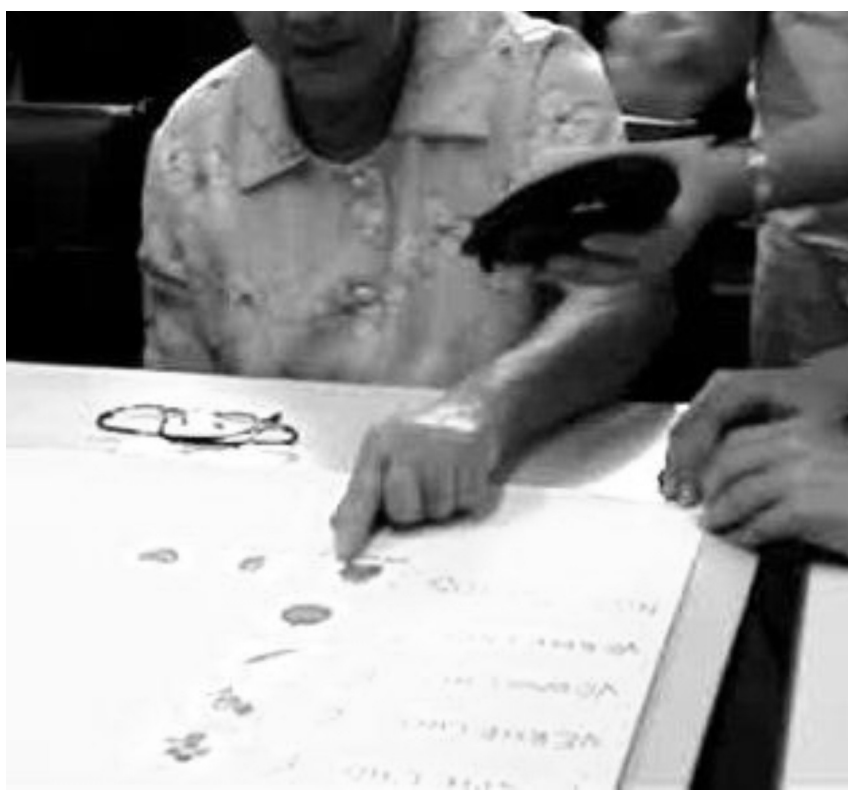

Figura 3. Do símbolo à palavra falada: "Amigos, amigos e coração"

Apresenta evidente esforço fonoarticulatório, acompanhado de tensão cervical e agudização da voz.

Grupo de CSA: Apesar de apresentar condições de oralidade, geralmente se mostra pouco falante nas atividades, porém sempre atenta e participativa. Tem papel importante no grupo, frequentemente resgatando fatos de todos os membros do grupo, apoiando-se, quando necessário, em registros da sua agenda.

Não apresentou dificuldades em compreender e utilizar a CSA, construindo enunciados longos por meio dos símbolos, geralmente com pouca necessidade de mediação. Verifica-se que os próprios símbolos se constituem como pista para sua produção linguística. Geralmente, após a construção do seu discurso por meio dos recursos da CSA, tenta reproduzir oralmente suas produções. Demonstrou satisfação quando lhe foi apresentado o símbolo de professora, sua profissão. Guardou-o espontaneamente para levar para casa, além de usálo com frequência nos encontros do Grupo CSA. Seus gestos e outras pistas, além do contexto, fornecem condições para que diferentes interlocutores possam contribuir na atividade discursiva e reflexiva de modo a conduzir à palavra desejada.

Como S3 apresenta a escrita preservada ofereceu-se, no início do estudo, a possibilidade de apontar no alfabeto as palavras que não conseguia falar. Nesta fase, os símbolos encontravam dispostos de modo fixo em uma prancha de comunicação trifolder (vide www.clik.com.br) para todos os sujeitos. Este sujeito demonstrou dificuldades e não se interessou por essa alternativa (uso do alfabeto), optando por escrever ou, preferencialmente, por tentar falar, buscando a palavra que lhe faltava. Acredita-se que uma das razões para a dificuldade no uso do alfabeto foi a utilização fixa das letras, o que não lhe propiciava um retorno visual do que pretendia dizer.

No decorrer do trabalho, a prancha de símbolos fixos foi substituída por outra disposta em velcro, que favorecia a mobilidade dos símbolos e a visualização dos enunciados construídos. Essa alternativa, que se mostrou mais produtiva para o grupo e para este sujeito, possibilitou a construção de enunciados mais longos e elaborados.
A CSA possibilita ao Sujeito 3, uma construção textual/ discursiva mais elaborada, que não seria possível diante de sua condição afásica. Segue exemplo de material produzido, em que o sujeito rapidamente construiu sua resposta por meio da prancha de comunicação quando se perguntou acerca das coisas de que gostava, prescindindo, inclusive, de mediação de interlocutores:

"Eu gosto (de ser) professora aposentada.

(Gosto dos) netos (crianças), filhos e família.

(Gosto de) plantas.

(Gosto de) comer frutas.

Comprar (coisas).

Ouvir música, fazer comida, assistir TV.

Dormir.

Eu gosto (de ir na) igreja."

Nesse texto, os símbolos apontados pelo sujeito foram transcritos ortograficamente, acrescentando-se os complementos implícitos em seu discurso (anotados entre parênteses), conforme interpretados pelo interlocutor.

Vale notar que, nesse episódio, o sujeito foi indagado como faria para responder todas essas coisas sem os símbolos. O sujeito S3 sorriu e fez gestos com as mãos, dando a entender que não seria possível oferecer a mesma resposta ao interlocutor. Em outra situação trouxe espontaneamente dados da sua história de vida, em material construído em sua casa por meio dos símbolos. Exemplos que evidenciam os benefícios da CSA para este sujeito.

\section{Sujeito 4}

Dados pessoais: 56 anos, gênero masculino, pedreiro, dois filhos. Vários AVCs resultaram em um quadro afásico complexo que comprometem sua fala, em que se reconhece uma afasia motora aferente com hemiplegia à direita. Apresenta estereotipias verbal e gestual, utilizando "opa" e gesto de um círculo, para perguntas e "óia" ao iniciar assuntos ou na tentativa de confirmar respostas. $\mathrm{O}$ isolamento social incomoda sua irmã/cuidadora e o leva a se ausentar de encontros familiares.

Grupo de CSA: Apesar das grandes dificuldades de linguagem, mostra-se participativo e interessado no grupo. Apresenta grande latência de tempo de resposta, o que, por vezes, gera ao interlocutor dúvidas sobre sua compreensão e demanda um tempo maior de resposta. Contudo, nem sempre lhe é dado o tempo necessário, em função, muitas vezes, da angústia que essa situação (de silêncio e espera) gera na relação dialógica. Nas situações que lhe interessam mais, embora menos frequentes (ou talvez menos evidentes ao interlocutor), mostra-se persistente. Insiste, geralmente, optando por escrever as letras no ar ou no papel, até que se chegue, com a mediação dos interlocutores, ao que pretende dizer, quando produz “opa” e sorri.

Além disso, este sujeito desenvolveu um modo peculiar de resposta com os símbolos da CSA, em que retira de cena (vira os símbolos ou os afasta), deixando o símbolo que representa a resposta desejada. Tal alternativa demanda maior tempo na situação de interlocução. Nas atividades de resgate da história de vida e do trabalho com profissões, demonstrou grande satisfação quando se comentou que ele havia sido pedreiro, o que reitera a importância do trabalho linguístico contextualizado 
e focado nas demandas e interesses dos sujeitos.

O trabalho com a CSA se mostrou bastante produtivo, sendo que a utilização do VoicePod mostrou-se como importante recurso facilitador de sua oralidade. Após anos sem ouvir sua voz, sua irmã pode ouvi-lo dizer seu apelido, utilizando-se desse equipamento.

Segue avaliação do grupo feita por esse sujeito (Figura 4), após alguns meses de trabalho:

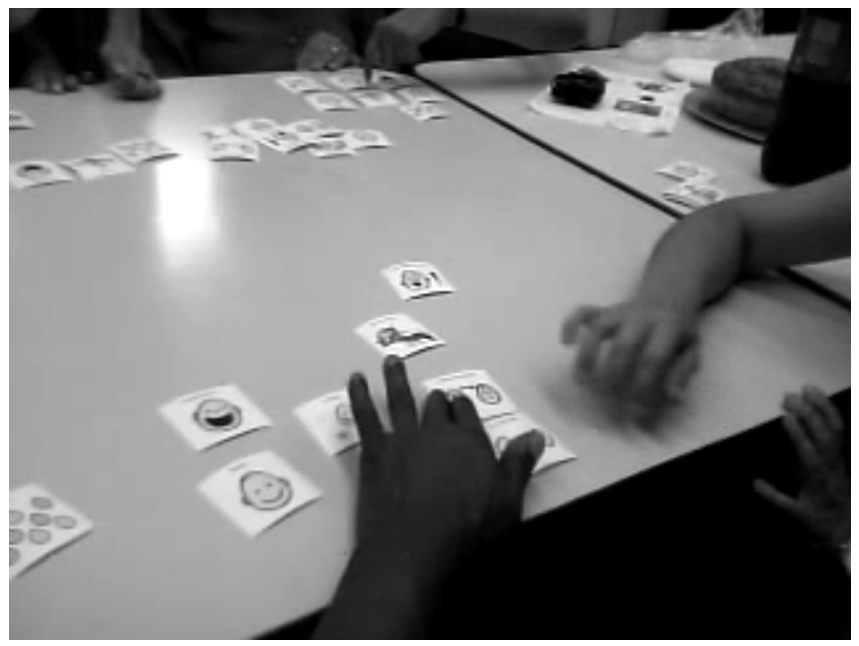

Figura 4. Avaliação do grupo pelo Sujeito 4: "O grupo foi bom para trocar ideias"

\section{Sujeito 5}

Dados pessoais: 64 anos, gênero masculino, casado, sete filhos (um falecido). Aprendeu a ler e escrever com a esposa. Como os outros sujeitos, não é fluente, apresentando afasia com expressão verbal reduzida. Sofreu AVC envolvendo os "lobos frontal, parietal e occipital e a porção superior do lobo esquerdo do cerebelo". Na infância, cantava e tocava música sertaneja com o irmão. Trabalhou em usina de açúcar, metalúrgica, fábrica de cerâmica, fábrica de cerveja, FEPASA e como vigilante. Após o AVC, deixou de fazer atividades de que gostava. Demonstra compreensão, comunicando-se por meio de gestos, desenho e produção oral de palavras isoladas. Observa-se que geralmente omite a sílaba inicial, levantando-se como hipótese para tal, o fato da esposa atuar oferecendo-lhe o incentivo oral.

Grupo de CSA: apresenta pouca iniciativa para falar, porém se mostra atento e participativo nas atividades. Geralmente apresenta um tempo grande de latência para responder, alegando que as dificuldades são decorrentes da falta de óculos, sendo que nem sempre os traz. Esse tempo de latência de resposta parece decorrer mais de suas dificuldades linguísticas do que das dificuldades visuais.

O trabalho com história de vida por meio dos símbolos mostrou-se muito produtivo, possibilitando que resgatasse/ contasse fatos significativos de sua vida. Nessa situação, a esposa também se envolveu mais com a proposta da CSA, contribuindo com fotos e relatos familiares. Após essas atividades e a introdução dos símbolos das profissões (Figura 5), o sujeito demonstrou grande motivação em levar a prancha de comunicação para casa.

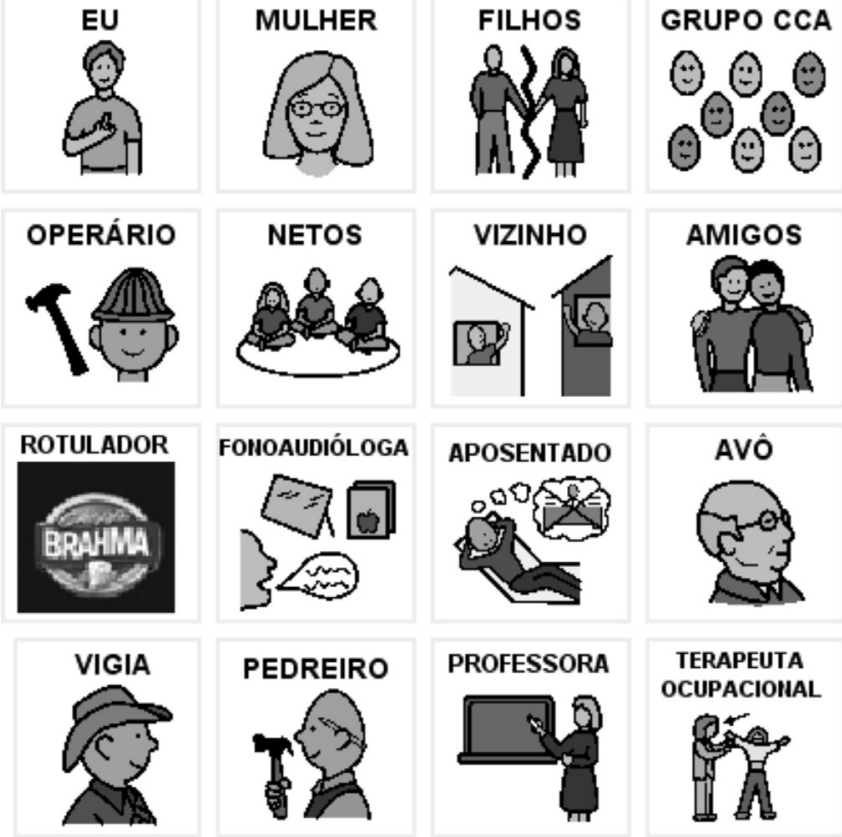

Figura 5. Símbolos de pessoas e profissões do Sujeito 5

\section{DISCUSSÃO}

Os resultados produzidos por afásicos, cuja fala é caracterizada por oralidade reduzida, evidenciam que a CSA possibilitou uma participação mais ativa nas situações de comunicação e contribuiu para maior qualidade das interações linguísticas e sociais.

Em outros trabalhos ${ }^{(11-13)}$, verifica-se que o uso da CSA não inibe a fala e pode favorecer a comunicação. Observa-se que os sujeitos afásicos se beneficiam dos recursos da CSA, adquirindo melhores possibilidades para se expressar, como demonstram os achados.

Autores de pesquisa realizada em 2004 ${ }^{(7)}$ apontam que pessoas com distúrbios adquiridos de comunicação podem se beneficiar da CSA, como demonstram estudos da área, para melhorar a efetividade da comunicação e a participação nas atividades de vida diária, o que corrobora nossos achados.

Como afirma outra pesquisadora brasileira ${ }^{(14)}$, sob a perspectiva da neurolinguística discursiva (ND) é possível uma nova leitura dos fenômenos patológicos da linguagem, o que possibilita entender, de um lado, as dificuldades que o afásico manifesta no uso da língua(gem) e, de outro, os processos de significação que o afásico pratica como solução para enfrentálas, como demonstram os resultados.

Os achados mostram as possibilidades de traduções, em termos jakobsonianos, por meio da linguagem/uso da CSA, ou seja, de operações semióticas do símbolo à palavra, do símbolo ao gesto, da palavra ao símbolo, bem como da circulação entre sistemas verbais e não-verbais, isto é, do símbolo da CSA à palavra. Evidencia ainda, o uso da CSA como importante alternativa de pista visual na afasia.

Os resultados demonstram que a CSA propiciou aos sujeitos, favorecimento da linguagem e uma construção textual mais elaborada, que não seria possível diante de sua condição afásica. 


\section{COMENTÁRIOS FINAIS}

Os achados mostram a contribuição da CSA nos diferentes processos de significação utilizados pelo sujeito afásico na tentativa de superar as condições linguísticas impostas pela patologia. De modo geral, verifica-se um uso da linguagem mais efetivo além de maior acesso ao que os sujeitos pretendem dizer, a partir da implementação da CSA em uma perspectiva discursiva.

Os resultados evidenciam que a CSA possibilitou maior participação dos sujeitos em diversas situações discursivas e contribuiu para a maior qualidade das interações linguísticas e sociais do grupo estudado. Verifica-se que a CSA, além de favorecer a linguagem em suas várias dimensões, também se constituiu como importante recurso de apoio visual para os sujeitos afásicos.

A perspectiva de linguagem adotada revela-se como fundamental para ampliar/superar a abordagem da CSA, do mero apontar/treinar figuras (símbolos) e do acionar teclas a novas possibilidades no acompanhamento fonoaudiológico de pessoas com afasia. Mostra, guardadas as devidas diferenças teórico-metodológicas, que o referencial discursivo possibilitou a essas pessoas, se colocarem como sujeitos linguísticos e sociais.

\section{AGRADECIMENTOS}

A autora agradece aos sujeitos da pesquisa, aos alunos de Fonoaudiologia colaboradores do estudo e à Profa. Dra. Maria Irma Hadler Coudry, responsável pelo Grupo II do CCA/IEL - UNICAMP - Campinas (SP), Brasil.

Ao Fundo de Apoio ao Ensino, à Pesquisa e à Extensão FAEPEX - da Universidade Estadual de Campinas pelo apoio concedido para realização dessa pesquisa sob processo número 1298/2006 e à Fundação de Amparo à Pesquisa do Estado de São Paulo (FAPESP) sob processo número 2006/57664.

\begin{abstract}
This work focuses on the study of Augmentative and Alternative Communication (AAC) in aphasia from a discursive perspective, assuming an original and fundamental character. It is of interest to investigate meaning attribution processes of non-fluent aphasic patients who use AAC through a qualitative longitudinal case report of five subjects with varied ages, linguistic deficits, and aphasia types, attended in a Speech-Language Pathology therapeutic group. Data were video-recorded from 2006 to 2008, and relevant episodes to the aims of the present investigation were analyzed. The results evidenced that AAC enables various meaning attribution processes. The subjects performed language translations, in jakobsonian terms: from symbol to word, from gesture to word, from drawing to word and the circulation between verbal and non-verbal systems. AAC was effective in the linguistic activities of the studied subjects, affecting the quality of their social interaction.
\end{abstract}

Keywords: Aphasia; Nonverbal communication; Language; Language therapy

\section{REFERÊNCIAS}

1. Radanovic M. Características do atendimento de pacientes com acidente vascular cerebral em hospital secundário. Arq Neuropsiquiatr. 2000;58(1):99-106.

2. Fedosse E. Acompanhamento fonoaudiológico de um sujeito afásico não-fluente: foco na continuidade sensório-motora. Distúrb Comun. 2007;19(3):403-14.

3. Tetzchner SV, Martinsen H. Introdução à comunicação aumentativa e alternativa. Portugal: Porto Editora; 2000.

4. Chun RYS, Fedosse E, Coudry MIH. Avaliação e acompanhamento fonoaudiológico de sujeitos não falantes. Diretrizes, Normas e Condutas - Área da Saúde, 2007 [Internet]. [citado 2009 Out 10]. Disponível em: http://www.fcm.unicamp.br/diretrizes/temas.html.

5. Garrett KL, Kimelman MDZ. AAC and aphasia: cognitive-linguistic considerations. In: Beukelman DR, Yorkston KM, Reichle J, editors. Augmentative and alternative communication for adults with acquired neurological disorders. Baltimore: Paul H. Brookes Publishing; 2000. p. 339-74.

6. Lasker JP, Bedrosian JL. Promoting acceptance of augmentative and alternative communication by adults with acquired communication disorders. Augment Altern Commun. 2001;17:141-53.

7. Jacobs B, Drew R, Ogletree BT, Pierce K. Augmentative and Alternative Communication (AAC) for adults with severe aphasia: where we stand and how we can go further. Disabil Rehabil. 2004;26(21-22):1231-40.

8. Koul R, Corwin M, Hayes S. Production of graphic symbol sentences by individuals with aphasia: efficacy of a computer-based augmentative and alternative communication intervention. Brain Lang. 2005;92(1):58-77.

9. Galli JFM, Oliveira JP, Deliberato D. Introdução da comunicação suplementar e alternativa na terapia com afásicos. Rev Soc Bras Fonoaudiol. 2009;14(3):402-10.

10. Di Nubila HBV, Buchalla CM. O papel das Classificações da OMS - CID e CIF nas definições de deficiência e incapacidade. Rev Bras Epidemiol. 2008;11(2):324-35.

11. Chun RYS. Comunicação suplementar e/ou alternativa: abrangência e peculiaridades dos termos e conceitos em uso no Brasil. Pró-Fono. 2009;21(1):69-74.

12. Chun RYS. Comunicação suplementar e/ou alternativa: favorecimento da linguagem de um sujeito não falante. Pró-Fono. 2003;15(1):55-64.

13. Trevizor TT, Chun RYS. O desenvolvimento da linguagem por meio do sistema pictográfico de comunicação. Pró-Fono. 2004;16(3):323-32.

14. Coudry MIH. Processos de significação no estudo discursivo da afasia. In: Anais do II Congresso Brasileiro de Comunicação Alternativa ISAAC Brasil. Campinas: UNICAMP; 2007.

15. Couto EAB. Utilização dos sinais aumentativos e alternativos de comunicação na reabilitação das afasias. In: Brasil Almirall C, Soro-Camats E, Bultó CR. Sistemas de sinais e ajudas técnicas para comunicação alternativa e a escrita: princípios teóricos e aplicações. São Paulo: Livraria Santos Editora; 2003. p.231-41. 